\title{
Molecular and histopathological detection of Hepatozoon canis in red foxes (Vulpes vulpes) from Portugal
}

Luís Cardoso ${ }^{1,2^{*}}$, Helder CE Cortes ${ }^{3}$, Osnat Eyal ${ }^{4}$, Antónia Reis ${ }^{3}$, Ana Patrícia Lopes ${ }^{1,5}$, Maria João Vila-Viçosa ${ }^{3}$, Paula A Rodrigues ${ }^{1,5}$ and Gad Baneth ${ }^{4}$

\begin{abstract}
Background: Hepatozoon canis is a protozoan tick-borne pathogen of dogs and wild canids. Hepatozoon spp. have been reported to infect foxes in different continents and recent studies have mostly used the polymerase chain reaction (PCR) for the detection and characterization of the infecting species. Surveying red foxes (Vulpes vulpes) may contribute to better understanding the epidemiology of canine vector-borne diseases, including hepatozoonosis caused by H. canis in domestic dogs. The present study investigated the prevalence of Hepatozoon spp. by means of histopathology and molecular analysis of different tissues in red foxes from different parts of Portugal.

Methods: Blood and tissues including bone marrow, heart, hind leg muscle, jejunum, kidney, liver, lung, popliteal or axillary lymph nodes, spleen and/or tongue were collected from 91 red foxes from eight districts in northern, central and southern Portugal. Tissues were formalin-fixed, paraffin-embedded, cut and stained with hematoxylin and eosin. Polymerase chain reaction (PCR) amplified a 250 bp fragment of the 18S rRNA gene of Hepatozoon spp. and the DNA products were sequenced.

Results: Hepatozoon canis was detected in 68 out of 90 foxes (75.6\%) from all the sampled areas by PCR and sequencing. Histopathology revealed $\mathrm{H}$. canis meronts similar in shape to those found in dogs in the bone marrow of $11(23.4 \%)$ and in the spleen of two (4.3\%) out of 47 foxes $(p=0.007)$. All the 11 foxes found positive by histopathology were also positive by PCR of bone marrow and/or blood. Positivity by PCR (83.0\%) was significantly higher $(p<0.001)$ than by histopathological examination $(23.4 \%)$ in paired bone marrow samples from the same 47 foxes. Sequences of the 18S rRNA gene of H. canis were $98-99 \%$ identical to those in GenBank.

Conclusions: Hepatozoon canis was found to be highly prevalent in red fox populations from northern, central and southern Portugal. Detection of the parasite by histopathology was significantly less sensitive than by PCR. Red foxes are a presumptive reservoir of $H$. canis infection for domestic dogs.
\end{abstract}

Keywords: Canine vector-borne diseases, Hepatozoon canis, Histopathology, Polymerase chain reaction, Portugal, Red fox, Vulpes vulpes

\footnotetext{
* Correspondence: Icardoso@utad.pt

'Department of Veterinary Sciences, School of Agrarian and Veterinary

Sciences, University of Trás-os-Montes e Alto Douro (UTAD), Vila Real,

Portugal

${ }^{2}$ Parasite Disease Group, Instituto de Biologia Molecular e Celular,

Universidade do Porto, Oporto, Portugal

Full list of author information is available at the end of the article
} 


\section{Background}

Hepatozoonosis caused by Hepatozoon canis is a canine vector-borne disease (CVBD) reported from the Old World and more recently also from South and North America [1]. The apicomplexan parasite H. canis (suborder Adeleorina: family Hepatozoidae) has a life cycle which involves vertebrates as intermediate hosts, including domestic dogs and wild canids, and ticks as definitive hosts [2].

Autochthonous infections with $H$. canis are prevalent in dogs from areas with tropical, subtropical or temperate climates, where their primary vector is the three-host tick species Rhipicephalus sanguineus, the brown dog tick $[3,4]$. Transmission of $H$. canis to the vertebrate hosts typically takes place by ingestion of the arthropod vector containing mature protozoal oocysts with infective sporozoites $[5,6]$. Nevertheless, intrauterine transmission from a dam to its pups has also been observed in $H$. canis infection [7]. No transfer during the vector blood feeding has been demonstrated for any Hepatozoon spp., including $H$. canis, as opposed to most vector-borne pathogens, which are transmitted by their invertebrate hosts via the salivary glands during a blood meal [2]. After ingestion of infected ticks, sporozoites invade mononuclear cells and disseminate via blood or lymph to different visceral organs of the vertebrate hosts, such as the bone marrow, spleen and lymph nodes, where they develop into the meront stage [1]. Merozoites infect leukocytes where the gamont stage of the protozoan, infective for the tick, is found later [8].

In dogs, infection with $H$. canis is often subclinical but may manifest as a mild to debilitating and even lifethreatening disease with cachexia, lethargy and anemia $[2,9]$. Hepatozoon canis is detectable by microscopic observation of circulating intracellular gamonts in stained blood smears [10]. The parasite can also be visualized in histopathological specimens, with micromerozoites aligned in a circle around a central opaque core forming the typical "wheel spoke"-pattern mature meront [6]. Molecular techniques, including the polymerase chain reaction (PCR) and real-time PCR are available for sensitive detection, genetic characterization and epidemiological studies of Hepatozoon spp. infections in blood and other tissues [11-15].

Red foxes (Vulpes vulpes) have been demonstrated to be infected with Hepatozoon spp. morphologically resembling $H$. canis [16] and as seropositive for the parasite [17] in areas where it is prevalent in domestic dogs. Moreover, $H$. canis infections were molecularly confirmed in red foxes in Spain [18], Slovakia [19], Croatia [20] and Italy [21]. Infections with Hepatozoon spp. other than $H$. canis have been reported in other species of foxes including the gray fox (Urocyon cinereoargenteus), the crab-eating fox (Cerdocyon thous) and the wild Pampas fox (Lycalopex gymnocercus) [22-24]. Surveying foxes, as hosts that share habitats with dogs, may contribute to a better understanding of the epidemiology of CVBD such as hepatozoonosis due to $H$. canis. The present study aimed at investigating the prevalence of Hepatozoon spp. by means of histopathology and molecular analysis in red foxes from different regions of Portugal.

\section{Methods}

Eighty-eight corpses of wild red foxes ( $V$. vulpes) shot during the official hunting season or killed in road accidents were obtained between November 2008 and March 2010. These animals originated from the districts of Viana do Castelo $(n=9)$, Bragança $(n=13)$, Vila Real $(n=20)$, Braga $(n=3)$ and Porto $(n=2)$, in the north; Aveiro $(n=2)$, in the centre; and Évora $(n=39)$, in the south of Portugal [25]. Two additional red foxes from the southern district of Setúbal and another one from Bragança were presented alive to the Center for Wildlife Rehabilitation, UTAD Veterinary Hospital (UTAD-VH).

The corpses were refrigerated (at $4^{\circ} \mathrm{C}$ ) for no more than $72 \mathrm{~h}$ or kept frozen (at $-20^{\circ} \mathrm{C}$ ) and thawed before collecting the samples. During necropsy, clotted blood was collected from the right atrium or chest cavity and bone marrow from the femoral bone, with sterile equipment, and stored at $-20^{\circ} \mathrm{C}$ until further processing. Blood from the jugular or cephalic veins of the three living foxes was collected into EDTA tubes and also kept under the same freezing conditions as above. This study was approved by the UTAD-VH ethical committee as complying with the Portuguese legislation for the protection of animals (Law no. 92/1995).

Out of 52 foxes whose gender was observed, 23 were females and 29 males; gender was not recorded for 39 of the 91 foxes. Age was determined by morphologic characteristics and tooth eruption pattern and wear [26] in 48 foxes and ranged from 1.0 to 7.5 years, with a median value of 2.5 years (interquartile range: $1.5-3.5$ ). Fourteen foxes were classified as juveniles (less than 2 years of age) and 34 as adults (2 years or more) [27].

Samples of heart, hind leg muscle (biceps femoris), jejunum, kidney, liver, lung, popliteal or axillary lymph nodes, spleen and tongue were further collected from 47 foxes of northern Portugal. For routine histopathological analysis, tissues were formalin-fixed, paraffin-embedded, cut at $3 \mu \mathrm{m}$ thickness and stained with hematoxylin and eosin (H\&E).

DNA was extracted from blood, bone marrow, heart, hind leg muscle, liver, lung, popliteal lymph node and spleen samples with commercial purification kits (QIAamp ${ }^{\odot}$ DNA Blood Mini or QIAamp ${ }^{\odot}$ DNA Mini; Qiagen, Valencia, CA, USA), according to the manufacturer's instructions. Polymerase chain reaction (PCR), using primers (125 nM each) Hep-F (5' -ATA CAT GAG CAA AAT CTC AAC-3') and Hep-R (5'-CTT ATT ATT CCA TGC TGC AG-3'), amplified an approximately 
$650 \mathrm{bp}$ partial sequence of the 18S rRNA gene of Hepatozoon spp. [15,28]. The following conditions were used for amplification: $95^{\circ} \mathrm{C}$ for $5 \mathrm{~min}$; 35 cycles of $95^{\circ} \mathrm{C}$ for $20 \mathrm{~s}$, $57^{\circ} \mathrm{C}$ for $30 \mathrm{~s}$, and $72^{\circ} \mathrm{C}$ for $90 \mathrm{~s}$; and $72^{\circ} \mathrm{C}$ for $5 \mathrm{~min}$. PCR was performed using Syntezza PCR-Ready High Specificity (Syntezza Bioscience, Jerusalem, Israel), with positive $(H$. canis) and negative control samples run with each reaction. PCR products were sequenced using the BigDye Terminator v3.1 Cycle Sequencing Kit and an ABI PRISM 3100 Genetic Analyzer (Applied Biosystems, Foster City, CA, USA), at the Center for Genomic Technologies, Hebrew University of Jerusalem, Israel. DNA sequences were evaluated with the ChromasPro software version 1.33 and compared for similarity to sequences available from GenBank, using the BLAST 2.2.9 program (http://www. ncbi.nlm.nih.gov/BLAST/).

For statistical analysis, the Chi-squared or Fisher's exact tests compared proportions of positivity. The McNemar's test was used to compare results obtained from paired samples (i.e., from the same animal). A $p$ value $<0.05$ was considered as statistically significant [29]. The exact binomial test estimated confidence intervals (CI) for proportions, with a 95\% confidence level. Analyses were done using StatLib or SPSS 11.5 software for Windows.

\section{Results}

Histopathology revealed Hepatozoon meronts with wheel spoke structure (Figure 1) in the bone marrow of 11 (23.4\%) out of the 47 examined foxes from the north of Portugal. Meronts were also found in the spleen (Figure 2) of two of those 11 positive foxes, thus representing $4.3 \%$ out of the 47 foxes $(p=0.007)$. No Hepatozoon developmental forms were detected in the remaining histopathological samples from other tissues (heart, hind leg

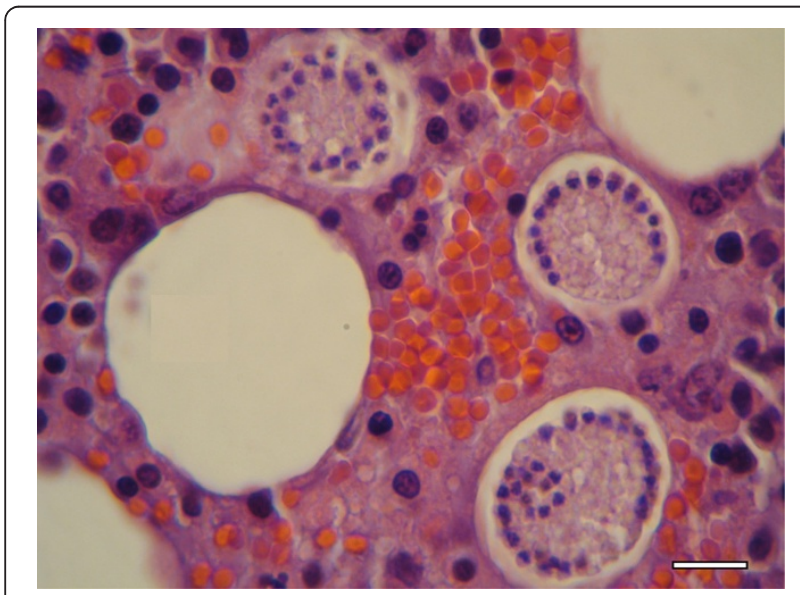

Figure 1 Bone marrow histopathological specimen from a red fox. Three mature meronts of $H$. canis with a typical wheel-spoke structure, containing micromerozoites aligned in a circle around a central opaque core (H\&E, scale-bar $=20 \mu \mathrm{m})$.

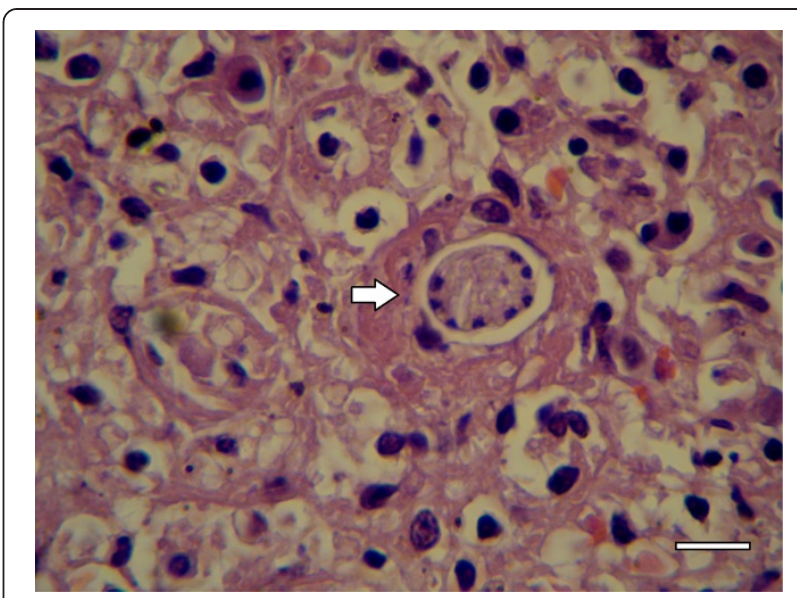

Figure 2 Spleen histopathological specimen from a red fox. A developing meront of $H$. canis (arrow) (H\&E, scale-bar $=20 \mu \mathrm{m})$.

muscle, jejunum, kidney, liver, lung, popliteal or axillary lymph nodes and tongue). No other histological abnormalities were observed in any of the tissues histologically examined. However, some samples showed autolytic alterations, in spite of the attempts to minimize postmortem effects.

By PCR and sequencing (Table 1 ), $H$. canis was detected in 68 out of 90 foxes (75.6\%; 95\% CI: 64.5-83.2\%), from all the eight sampled districts. Hepatozoon canis was identified in $40(81.6 \%)$ out of 49 foxes from the northern/central districts and in 28 (68.3\%) out of the 41 foxes from the southern districts (Table 1). Due to discrepancy in the number of paired DNA samples between north/centre and south, statistical comparison of blood and bone marrow combined results was not performed by geographical region. In fact, 50 blood and 47 paired bone marrow samples were available from the 50 northern/central foxes, whereas only two paired blood samples were tested for 32 bone marrow samples among the 41 southern foxes.

PCR for Hepatozoon spp. was positive in 36 (73.5\%) of 49 DNA blood samples and 39 (79.6\%) of 49 paired bone marrow samples, with no statistically significant difference between positivity in the blood and bone marrow $(p=0.375)$. Based on blood and bone marrow combined sequencing results, 19 (82.6\%) female and 23 (82.1\%) male foxes were positive for $H$. canis. There were $10(71.4 \%)$ juvenile and $28(84.8 \%)$ adults positive for $H$. canis, also based on combined sequencing results from blood and bone marrow. Differences were not statistically significant between genders $(p=0.419)$ or age groups $(p=1.0)$.

Positivity by PCR (83.0\%) was significantly higher $(p<0.001)$ than by histopathological examination $(23.4 \%)$ in paired bone marrow samples from the same 47 foxes. All the 11 foxes found positive by histopathology were also positive by PCR of bone marrow and/or blood. The 
Table 1 Results of PCR for Hepatozoon spp. and sequencing from blood and bone marrow DNA samples of red foxes from Portugal

\begin{tabular}{lllll}
\hline Region in Portugal & \multicolumn{2}{l}{ No. of positive foxes/no. of foxes tested (\%) } \\
\cline { 2 - 5 } & PCR - blood & PCR - bone marrow & $\begin{array}{l}\text { PCR - blood and/or } \\
\text { bone marrow }\end{array}$ & $\begin{array}{l}\text { PCR and sequencing identifying } \\
\text { H. canis - blood and/or bone marrow }\end{array}$ \\
\hline North and centre & $37 / 50(74.0)$ & $39 / 47(83.0)$ & $41 / 50(82.0)$ & $40 / 49(81.6)$ \\
South & $6 / 11(54.5)$ & $23 / 32(71.9)$ & $29 / 41(70.7)$ & $28 / 41(68.3)$ \\
Total & $43 / 61(70.5)$ & $62 / 79(78.5)$ & $70 / 91(76.9)$ & $68 / 90(75.6)$ \\
\hline
\end{tabular}

presence of $H$. canis in multiple different tissues was assessed by PCR in a subset of six foxes positive by histopathology of bone marrow and in six foxes negative by histopathology but positive by PCR in blood. No statistically significant differences were found between the two subsets by comparing the proportion of positive PCR results between histopathology-positive and -negative foxes for the same tissues (Table 2).

Of the 18S rRNA DNA sequences obtained by sequencing of the PCR product and searching for the closest GenBank match, 40 sequences from the northern/central red foxes were 98-99\% identical to GenBank GU376457 (H. canis from an Italian red fox [21]). Of the sequences from the southern foxes, 22 were 99\% identical to GU376457, four were 99\% identical to EU289222 (H. canis from a Taiwanese dog), one was 99\% identical to AY150067 (H. canis from a Spanish red fox [30]) and another was 99\% identical to FJ608736 (H. canis from an Italian dog).

\section{Discussion}

A high prevalence of $H$. canis infection in foxes has been found by PCR in surveys from several countries in southern Europe. By blood PCR the prevalence of $H$. canis in red foxes from northern Spain (28.6\% [2/7]) [31] was considerably lower than that found in the blood of foxes from Portugal in this study (70.5\%). By spleen PCR, the prevalence levels of $H$. canis in red foxes were 90\% (18/20) in central Spain [18], 23.0\% (44/191) in Croatia [20] and $16.4 \%(16 / 119)$ in Italy [21]. In a previous study from southern Portugal, 143 (48\%) out of 301 red foxes assessed by microscopy of blood, bone marrow and impression smears of spleen and lymph node, were found infected with meronts or gamonts [16]. In Israel, by means of an enzyme-linked immunosorbent assay, 20 (23.8\%) out of 84 fox sera tested were positive for antibodies to $H$. canis [17]. The diversity of results observed among studies may represent distinct prevalence levels by geographical localization, but may also derive from different techniques used, such as serology indicating exposure and PCR detecting infection, or different tissues sampled [32].

The presence of $H$. canis in striated muscle has been a point of debate as it was detected by PCR in the heart and striated muscle tissues of red foxes from Slovakia [19]. Although Hepatozoon americanum, a species found in North America, primarily infects skeletal and cardiac muscles [33], this is not the case for $H$. canis, which mostly infects hemolymphoid tissues of domestic dogs [2]. In the present study, spleen, heart and hind leg muscle samples from 12 foxes were selected for PCR based on previous histopathological or blood-PCR positivity. Our study also indicated that fox muscle tissues were positive by PCR for $H$. canis, but no histopathological evidence for infection of muscle cells was found in the 12 foxes from which multiple tissues were studied. The lack of histopathological evidence for infection of fox muscles by $H$. canis, yet the positive PCR of these tissues, could be due to a low level of true infection in the muscle itself missed by histopathology, or more likely to trapping of parasite from blood or hemolymphoid tissue in the sampled muscles. The autolytic process could have also contributed to a lower sensitivity of the histopathological analysis. In the present study, Hepatozoon spp. meronts were found by histopathology only in bone marrow (Figure 1) and spleen (Figure 2), with the former yielding a higher level of detection than any other tissue. This finding reinforces the idea that merogony occurs mainly in the bone marrow of red foxes, as previously suggested [16]. In addition, the present study represents the first comparison of histopathology and PCR for the

Table 2 Hepatozoon spp. PCR results in eight tissues of foxes found with (positive) or without (negative) wheel-spoke meronts by histopathological examination of bone marrow

\begin{tabular}{|c|c|c|c|c|c|c|c|c|}
\hline \multirow[t]{2}{*}{ Histopathology } & \multicolumn{8}{|c|}{ PCR (no. of positive samples/no. of samples tested) } \\
\hline & Blood & Bone marrow & Heart & Hind leg muscle & Liver & Lung & Lymph node & Spleen \\
\hline Positive $(n=6)$ & $5 / 6$ & $6 / 6$ & $6 / 6$ & $4 / 6$ & $6 / 6$ & $6 / 6$ & $6 / 6$ & $6 / 6$ \\
\hline Negative $(n=6)$ & $6 / 6^{*}$ & $6 / 6$ & $4 / 6$ & $3 / 6$ & $5 / 6$ & $6 / 6$ & $5 / 6$ & $5 / 6$ \\
\hline
\end{tabular}

* Inclusion of histopathologically negative foxes was based on a positive blood PCR result. 
detection of $H$. canis in red foxes, with the latter demonstrated to be significantly more sensitive for that purpose.

The vector of $H$. canis, the three-host tick $R$. sanguineus, has been found to infest mammalian hosts from all the 18 districts of continental Portugal [34]. The transmission of $H$. canis in ticks may occur transstadially from larvae to nymphs [35] and from these to the adult stages of $R$. sanguineus [8]. Both nymphs and adults containing $H$. canis sporozoites within oocysts can infect canids upon ingestion of ticks. Transovarial transmission, i.e. from female ticks to eggs, has not been demonstrated for $H$. canis [35]. Vertical intrauterine transmission of $H$. canis [7] might also contribute to the spread of this infection and explain its high prevalence in foxes. The fact that there was no difference between the prevalence of infection in juvenile and adult foxes might indicate that foxes are infected at a young age, by a vector or by transplacental transmission. Another mode of transmission not yet demonstrated for $H$. canis, but that could be associated with foxes, is predation by a canid host on another intermediate host, as shown for $H$. americanum [36].

In general, the high prevalence levels of Hepatozoon spp. found in red foxes contrasts with the much lower prevalence levels in dogs from the same geographical areas [16,21,37]. Out of 331 dogs from kennels and shelters in southern Portugal, 21.1\% were found to be positive for $H$. canis by PCR in blood [38]. Another recent investigation that molecularly assessed 320 cats from northern and central Portugal did not reveal any cat PCR-positive for $H$. canis, but $15.6 \%$ of the animals were PCR-positive for Hepatozoon felis [39]. Hepatozoon canis is orally transmitted by ingestion of infected ticks, and foxes are probably more likely than dogs or cats to accidentally ingest arthropods, by feeding more often on live prey or carrion [30]. With such a high prevalence of infection as shown in the present study in Portugal, foxes are likely to be a major reservoir of $H$. canis for domestic dogs. Interestingly, foxes existed in the world long before there were domestic dogs [40] and could be speculated to have been the original source of $H$. canis to other wild and domestic canids.

Some of the partial $H$. canis $18 \mathrm{~S}$ rRNA gene sequences obtained from foxes in the present study are most similar to those previously identified in Spanish and Italian red foxes (GenBank AY150067 and GU376457, respectively). However, $H$. canis sequences found in European foxes are also very similar to those found in dogs in the same countries. Therefore, the epizootiological importance of possible fox $H$. canis strains needs to be studied further and with longer DNA sequences before conclusions on such strains can be deduced [20,32].

\section{Conclusions}

In conclusion, $H$. canis has been demonstrated to be highly prevalent in red fox populations from northern/central and southern Portugal. Detection of $H$. canis by histopathology was shown to be significantly less sensitive than PCR. The high prevalence of $H$. canis in red foxes indicates that they are likely to be a major reservoir for infection of domestic dogs.

\section{Competing interests}

The authors declare that they have no competing interests.

\section{Authors' contributions}

LC designed the study, collected samples, analysed data and wrote the manuscript; HCEC designed the study, collected samples and assisted in drafting the manuscript; OE performed PCR and sequencing, and analysed data; AR, APL and MJV-V collected samples; PAR collected samples, performed histopathology and analysed data; GB designed the study, performed PCR and sequencing, analysed data and revised the manuscript. All authors read and approved the final version of the manuscript.

\section{Acknowledgments}

For their assistance in obtaining red fox samples, the authors would like to express their gratitude to: Eng. Teresa Coutinho, Dr. Roberto Sargo, Prof. Carlos Venâncio and Prof. Adelina Gama (UTAD), Dr. Margarida Simões (University of Évora), Eng. Rogério Rodrigues, Eng. Vítor Rego, Eng. Álvaro Gonçalves, Eng. Augusto Maia and Mr. Manuel Pinho (Forestry Regional Directorate of North, National Forestry Authority, Ministry of Agriculture), Captain Diamantino Fernandes (National Gendarmerie, Territorial Detachment of Vila Real), Mr. Miguel Arantes (Hunters Association of Vitorino dos Piães, Ponte de Lima), Chief Domingos Morais (Hunting and Fishing Recreational Club of Amares), Mr. Vasco Vaz (Hunting and Fishing Association of the Parish of Donai, Bragança), Mr. Vítor Pires ("São Martinhense" Hunting and Fishing Association, Miranda do Douro), Eng. Inácio Alves and Mr. Raul Fernandes (Hunting and Fishing Association of the Parish of Salselas, Macedo de Cavaleiros), Mr. Licínio Inocentes (Hunting and Fishing Club of Tâmega Raia Norte, Chaves), Dr. Mafalda Pinto-Basto (Faculty of Sciences, University of Lisbon) and fox hunting expert Dr. Miguel Fernandes and his team (Évora). Publication of the CVBD9 thematic series has been sponsored by Bayer HealthCare - Animal Health division.

\section{Author details}

${ }^{1}$ Department of Veterinary Sciences, School of Agrarian and Veterinary Sciences, University of Trás-os-Montes e Alto Douro (UTAD), Vila Real, Portugal. ${ }^{2}$ Parasite Disease Group, Instituto de Biologia Molecular e Celular, Universidade do Porto, Oporto, Portugal. ${ }^{3}$ Victor Caeiro Laboratory of Parasitology, Instituto de Ciências Agrárias e Ambientais Mediterrânicas, Universidade de Évora, Évora, Portugal. ${ }^{4}$ Koret School of Veterinary Medicine, The Hebrew University of Jerusalem, Rehovot, Israel. ${ }^{5}$ Animal and Veterinary Research Centre, UTAD, Vila Real, Portugal.

Received: 8 December 2013 Accepted: 11 January 2014

Published: 24 March 2014

\section{References}

1. Baneth G: Hepatozoonosis - Hepatozoon canis infection. In Infectious Diseases of the Dog and Cat. 4th edition. Edited by Greene CE. St. Louis: Elsevier Saunders; 2012:750-757.

2. Baneth G: Perspectives on canine and feline hepatozoonosis. Vet Parasitol 2011, 181:3-11.

3. Dantas-Torres F, Latrofa MS, Annoscia G, Giannelli A, Parisi A, Otranto D: Morphological and genetic diversity of Rhipicephalus sanguineus sensu lato from the New and Old Worlds. Parasit Vectors 2013, 6:213.

4. Dantas-Torres F, Capelli G, Giannelli A, Ramos RA, Lia RP, Cantacessi C, de Caprariis D, De Tommasi AS, Latrofa MS, Lacasella V, Tarallo VD, Di Paola G, Qurollo B, Breitschwerdt E, Stanneck D, Otranto D: Efficacy of an imidacloprid/ flumethrin collar against fleas, ticks and tick-borne pathogens in dogs. Parasit Vectors 2013, 6:245.

5. Christophers SR: The sexual life cycle of Leucocytozoon canis in the tick. Sci Mem Off Med Sanit Dep Gov India 1907, 28:1-11.

6. Baneth G, Samish M, Shkap V: Life cycle of Hepatozoon canis (Apicomplexa: Adeleorina: Hepatozoidae) in the tick Rhipicephalus sanguineus and domestic dog (Canis familiaris). J Parasitol 2007, 93:283-299. 
7. Murata T, Inoue M, Tateyama S, Taura Y, Nakama S: Vertical transmission of Hepatozoon canis in dogs. J Vet Med Sci 1993, 55:867-868.

8. Baneth G, Samish M, Alekseev E, Aroch I, Shkap V: Transmission of Hepatozoon canis to dogs by naturally-fed or percutaneously-injected Rhipicephalus sanguineus ticks. J Parasitol 2001, 87:606-611.

9. Baneth $\mathrm{G}$, Weigler $\mathrm{B}$ : Retrospective case-control study of hepatozoonosis in dogs in Israel. J Vet Intern Med 1997, 11:365-370.

10. Otranto D, Dantas-Torres F, Weigl S, Latrofa MS, Stanneck D, Decaprariis D, Capelli G, Baneth G: Diagnosis of Hepatozoon canis in young dogs by cytology and PCR. Parasit Vectors 2011, 4:55.

11. Baneth G, Barta JR, Shkap V, Martin DS, Macintire DK, Vincent-Johnson N: Genetic and antigenic evidence supports the separation of Hepatozoon canis and Hepatozoon americanum at the species level. J Clin Microbiol 2000, 38:1298-1301.

12. Baneth G, Sheiner A, Eyal O, Hahn S, Beaufils JP, Anug Y, Talmi-Frank D: Redescription of Hepatozoon felis (Apicomplexa: Hepatozoidae) based on phylogenetic analysis, tissue and blood form morphology, and possible transplacental transmission. Parasit Vectors 2013, 6:102.

13. Criado-Fornelio A, Buling A, Cunha-Filho NA, Ruas JL, Farias NA, Rey-Valeiron C, Pingre JL, Etievant M, Barba-Carretero JC: Development and evaluation of a quantitative PCR assay for detection of Hepatozoon sp. Vet Parasitol 2007 150:352-356.

14. Oyamada M, Davoust B, Boni M, Dereure J, Bucheton B, Hammad A, Itamoto K, Okuda M, Inokuma H: Detection of Babesia canis rossi, B. canis vogeli, and Hepatozoon canis in dogs in a village of eastern Sudan by using a screening PCR and sequencing methodologies. Clin Diagn Lab Immunol 2005, 12:1343-1346.

15. Sasanelli M, Paradies P, Greco B, Eyal O, Zaza V, Baneth G: Failure of imidocarb dipropionate to eliminate Hepatozoon canis in naturally infected dogs based on parasitological and molecular evaluation methods. Vet Parasitol 2010, 171:194-199.

16. Conceição-Silva FM, Abranches P, Silva-Pereira MC, Janz JG: Hepatozoonosis in foxes from Portugal. J Wildl Dis 1988, 24:344-347.

17. Fishman Z, Gonen L, Harrus S, Strauss-Ayali D, King R, Baneth G: A serosurvey of Hepatozoon canis and Ehrlichia canis antibodies in wild red foxes (Vulpes vulpes) from Israel. Vet Parasitol 2004, 119:21-26.

18. Criado-Fornelio A, Ruas JL, Casado N, Farias NA, Soares MP, Müller G, Brumt JG, Berne ME, Buling-Saraña A, Barba-Carretero JC: New molecular data on mammalian Hepatozoon species (Apicomplexa: Adeleorina) from Brazil and Spain. J Parasitol 2006, 92:93-99.

19. Majláthová V, Hurníková Z, Majláth I, Petko B: Hepatozoon canis infection in Slovakia: imported or autochthonous? Vector Borne Zoonotic Dis 2007, 7:199-202.

20. Deždek D, Vojta L, Ćurković S, Lipej Z, Mihaljević Ž, Cvetnić Ž, Beck R: Molecular detection of Theileria annae and Hepatozoon canis in foxes (Vulpes vulpes) in Croatia. Vet Parasitol 2010, 172:333-336.

21. Gabrielli S, Kumlien S, Calderini P, Brozzi A, lori A, Cancrini G: The first report of Hepatozoon canis identified in Vulpes vulpes and ticks from Italy. Vector Borne Zoonotic Dis 2010, 10:855-859.

22. Allen KE, Yabsley MJ, Johnson EM, Reichard MV, Panciera RJ, Ewing SA, Little SE: Novel Hepatozoon in vertebrates from the southern United States. J Parasitol 2011, 97:648-653.

23. Giannitti F, Diab SS, Uzal FA, Fresneda K, Rossi D, Talmi-Frank D, Baneth G: Infection with a Hepatozoon sp. closely related to Hepatozoon felis in a wild Pampas gray fox (Lycalopex - Pseudalopex - gymnocercus) coinfected with canine distemper virus. Vet Parasitol 2012, 186:497-502.

24. Almeida AP, Souza TD, Marcili A, Labruna MB: Novel Ehrlichia and Hepatozoon agents infecting the crab-eating fox (Cerdocyon thous) in southeastern Brazil. J Med Entomol 2013, 50:640-646.

25. Cardoso L, Cortes HC, Reis A, Rodrigues P, Simões M, Lopes AP, Vila-Viçosa MJ, Talmi-Frank D, Eyal O, Solano-Gallego L, Baneth G: Prevalence of Babesia microti-like infection in red foxes (Vulpes vulpes) from Portugal. Vet Parasitol 2013, 196:90-95.

26. Saénz-de-Buruaga M, Lucio AJ, Purroy J: Reconocimiento de Sexo y Edad en Especies Cinegéticas. Gobierno Provincial de Álava: Vitoria-Gasteiz; 1991.

27. Davidson RK, Gjerde B, Vikøren T, Lillehaug A, Handeland K: Prevalence of Trichinella larvae and extra-intestinal nematodes in Norwegian red foxes (Vulpes vulpes). Vet Parasitol 2006, 136:307-316.

28. Inokuma H, Okuda M, Ohno K, Shimoda K, Onishi T: Analysis of the $18 \mathrm{~S}$ rRNA gene sequence of a Hepatozoon detected in two Japanese dogs. Vet Parasitol 2002, 106:265-271.
29. Petrie A, Watson P: Statistics for Veterinary and Animal Science. 2nd edition. Oxford: Blackwell Publishing; 2006.

30. Criado-Fornelio A, Martinez-Marcos A, Buling-Saraña A, Barba-Carretero JC: Molecular studies on Babesia, Theileria and Hepatozoon in southern Europe. Part I. Epizootiological aspects. Vet Parasitol 2003, 113:189-201.

31. Gimenez C, Casado N, Criado-Fornelio A, de Miguel FA, Dominguez-Peñafiel G: A molecular survey of Piroplasmida and Hepatozoon isolated from domestic and wild animals in Burgos (northern Spain). Vet Parasitol 2009, 26:147-150.

32. Criado-Fornelio A, Rey-Valeiron C, Buling A, Barba-Carretero JC, Jefferies R, Irwin P: New advances in molecular epizootiology of canine hematic protozoa from Venezuela, Thailand and Spain. Vet Parasitol 2007, 144:261-269.

33. Little SE, Allen KE, Johnson EM, Panciera RJ, Reichard MV, Ewing SA: New developments in canine hepatozoonosis in North America: a review. Parasit Vectors 2009, 2(Suppl 1):S5.

34. Caeiro V: General review of tick species present in Portugal. Parassitologia 1999, 41(Suppl 1):11-15.

35. Giannelli A, Ramos RA, Di Paola G, Mencke N, Dantas-Torres F, Baneth G, Otranto D: Transstadial transmission of Hepatozoon canis from larvae to nymphs of Rhipicephalus sanguineus. Vet Parasitol 2013, 196:1-5.

36. Johnson EM, Panciera RJ, Allen KE, Sheets ME, Beal JD, Ewing SA, Little SE: Alternate pathway of infection with Hepatozoon americanum and the epidemiologic importance of predation. J Vet Intern Med 2009, 23:1315-1318.

37. Cassini R, Zanutto S, Frangipane di Regalbono A, Gabrielli S, Calderini P, Moretti A, Tampieri MP, Pietrobelli M: Canine piroplasmosis in Italy: epidemiological aspects in vertebrate and invertebrate hosts. Vet Parasitol 2009, 165:30-35.

38. Menn B, Lorentz S, Naucke TJ: Imported and travelling dogs as carriers of canine vector-borne pathogens in Germany. Parasit Vectors 2010, 3:34.

39. Vilhena H, Martinez-Díaz VL, Cardoso L, Vieira L, Altet L, Francino O, Pastor J, Silvestre-Ferreira AC: Feline vector-borne pathogens in the north and centre of Portugal. Parasit Vectors 2013, 6:99.

40. Lindblad-Toh K, Wade CM, Mikkelsen TS, Karlsson EK, Jaffe DB, Kamal M, Clamp M, Chang JL, Kulbokas EJ 3rd, Zody MC, Mauceli E, Xie X, Breen M, Wayne RK, Ostrander EA, Ponting CP, Galibert F, Smith DR, DeJong PJ, Kirkness E, Alvarez P, Biagi T, Brockman W, Butler J, Chin CW, Cook A, Cuff J, Daly MJ, DeCaprio D, Gnerre S, et al: Genome sequence, comparative analysis and haplotype structure of the domestic dog. Nature 2005, 438:803-819.

\section{doi:10.1186/1756-3305-7-113}

Cite this article as: Cardoso et al:: Molecular and histopathological detection of Hepatozoon canis in red foxes (Vulpes vulpes) from Portugal. Parasites \& Vectors 2014 7:113.

\section{Submit your next manuscript to BioMed Central and take full advantage of:}

- Convenient online submission

- Thorough peer review

- No space constraints or color figure charges

- Immediate publication on acceptance

- Inclusion in PubMed, CAS, Scopus and Google Scholar

- Research which is freely available for redistribution 